\title{
Development of Information and Communication Technology-based Resource Kit in Teaching Poetry
}

\author{
Ronald Candy S. Lasaten and Marlina L. Lino
}

\begin{abstract}
To address the need for ICT-based poetry teaching among the literature teachers of the Mariano Marcos State University College of Teacher Education, Laoag City, this study aimed at developing ICT-based resource kit in the teaching of poetry using the Research and Development (R\&D) methodology. A panel of literature experts and ICT experts validated the resource kit in terms of its content and design characteristics, respectively, using two different validation checklists. The validity of the ICT-based resource kit was established using computed weighted means. Findings show that the resource kit developed consists of a facilitator's guide and an interactive compact disc (CD) containing the ICT-based lessons in poetry. Both the facilitator's guide and the interactive $C D$ have their own salient parts and features that address the need for poetry pedagogy. Further, results show that the ICT-based resource kit is valid in terms of its content and design characteristics. Thus, the resource kit developed could help address the need of literature teachers for available ICT-based material in the teaching of poetry.
\end{abstract}

Index Terms-Information and communication technology-based (ICT-based) lesson, resource kit, teaching poetry.

\section{INTRODUCTION}

The search for quality education has been an elusive dream for Filipino educators. While there are dramatic and significant changes made in the curriculum, educators need to see convincing evidence that would otherwise prove an outstanding performance of the majority of Filipino students.

Yet, in spite of the various short or long term courses, seminars, workshops and conferences being offered, attended to and participated in by educators in order to enhance their competencies, many teachers still conform to the traditional approach to teaching and the quality in the performance of students still has to become known.

Literature instruction has long been at the center of the curriculum in all schools. However, it has undergone little systematic improvement. Teachers of literature are confined to the traditional method of teaching, resembling a one-person show with a captive audience. As a result, some students, if not most of them, suffer from mental indigestion or they do not learn at all since they have no choice but to swallow information fed to them [1].

Manuscript received February 15, 2017; revised June 27, 2017.

R. C. S. Lasaten is with the Mariano Marcos State University College of Teacher Education (MMSU-CTE), Laoag City, 2900, Philippines (e-mail: ronaldlasaten@gmail.com).

M. L. Lino is with the Mariano Marcos State University College of Arts and Sciences (MMSU CAS), City of Batac, 2906, Philippines ( email: mlino_mmsu@yahoo.com).
According to Ibsen [2], literature teachers are confined to traditional approach of teaching literature due to lack of instructional materials to use. They rely too much on textbooks as learning resources and rarely supplement lessons with learning materials and activities to foster students' understanding of literary selections.

Apparently, such argument holds true to literature teachers at the Mariano Marcos State University, College of Teacher Education (MMSU CTE) considering that they have been trained along basic Information and Communication Technology (ICT) skills. In fact, these teachers feel the need to apply these learned skills to innovate and revolutionize their instruction, particularly in the teaching of poetry. However, they are refrained from doing so due to lack of ready-to-use ICT-based resource materials in the teaching of such literary genre.

In an interview conducted among the literature teachers, four out of five admitted that they have difficulty teaching poetry. For them, simply using learning resource materials and textbooks is not enough. As a result, they often assign their students for group reports to be delivered in class. If not, they ask their students to read a poem at home and prepare for the lecture the following meeting. At times, they ask their students to read a poem aloud in class then a simple question-and-answer activity follows or they give full-length lecture on the poem read.

Such classroom scenario, according to Fernandez [3], brings about low productivity, social withdrawal, distrust to evaluations, depression, anxiety and other psychological problems. Furthermore, this separates students unnecessarily and denies them the opportunity to learn and interact with each other in ways that will foster their academic and social growth.

Meanwhile, the literature students expressed their sentiments towards literature learning, particularly poetry. Many of them do not find literature interesting. Some even consider it very threatening because the strategies employed by their teachers emphasize on learning the answers rather than the inquiry of questions, memorizing at the expense of critical thinking, focusing on bits and pieces of information instead of understanding in context, plain reciting instead of expressing arguments and reading aloud instead of doing.

In an interview conducted among students, they disclosed that the activities employed by their teachers in teaching poetry fail to encourage them to work together and to share freely ideas and bits of information with each other. The activities refrain them from using existing tools to extend their intellectual potentials and capabilities. Thus, the students find their literature class teacher-centered. 
The paramount aspiration of the researcher to address the need of a ready-to-use ICT-based material in teaching poetry that could respond to the aforementioned concerns prompted him to develop ICT-based resource kit in the teaching of poetry.

\section{OBJECTIVES OF THE STUDY}

This study aimed to develop and validate ICT-based resource kit in teaching poetry.

More specifically, it sought to determine the salient features of the ICT-based resource kit developed. Further, it sought to investigate the validity of the resource kit in terms of its content and design characteristics.

\section{THEORETICAL AND CONCEPTUAL FRAMEWORK}

Students are the main concern in the learning process. Hence, it is important to consider their needs and abilities. Learning is most meaningful when students themselves are actively engaged in creating, understanding and connecting to knowledge [4]. Moreover, students' motivation to learn is improved. Actual learning and performance of the students are enhanced for they are included in the decision-making processes in the classroom.

To move towards this ideal, this study is anchored on the Theory of Constructivism. The theory views students as active participants rather than as passive recipients of information in the learning process [5]. Ideas and concepts are learned both through systematized body of experiences and from casual everyday experiences. By providing a conducive learning environment, the students feel that they own the concept, and that they are free to manipulate and organize the concepts they have acquired and learned. When new information comes in, they are able to place the new concept in its right place in their memory network thus reducing their difficulty for retrieval.

In addition to the said perspective, Ora'a [6] agreed that to learn is to experience, that is, to interact with one's environment; to do, to feel, to sense, to handle, to perceive and so on, the opportunities that present themselves to the learners.

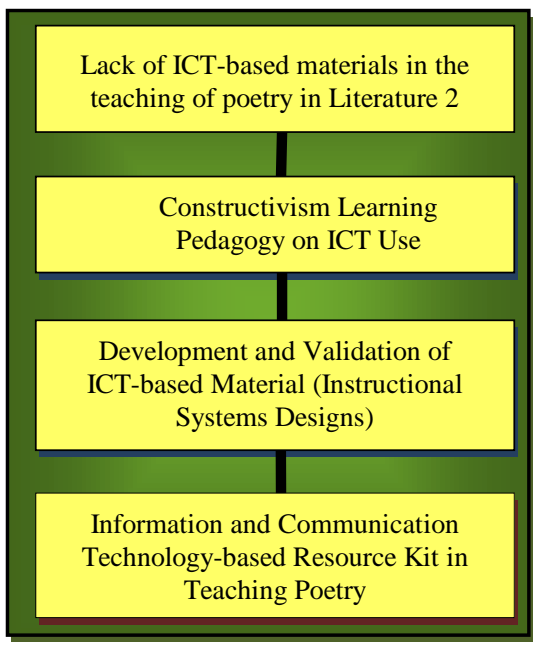

Fig. 1. The Research paradigm.
Fig. 1 shows the conceptual paradigm of the study. It can be gleaned from the figure that the lack of ICT-based resource materials in teaching poetry prompted the researcher in developing ready-to-use ICT-based resource kit in teaching poetry. Apparently, the ICT-based resource kit is intended for tertiary level, specifically for Literature 2 (Literatures of the World) classes.

It can also be revealed from the figure that the developed ICT-based resource kit was designed based on the learning principles of Constructivism highlighted by the use of ICT with special consideration on ICT learning pedagogies and the instructional systems designs for developing and validating of ICT-based resource materials.

The researcher believes that the developed ICT-based resource kit could address the need of literature teachers of an available ICT-based resource kit in teaching poetry in Literature 2 (Literatures of the World). Moreover, the resource kit is hoped to respond to the need for poetry pedagogy to transform literature instruction from teacher-centered to student-centered instruction.

\section{Methodology}

This study focused on the development and validation of ICT-based materials in teaching poetry and made use of the research and development (R \& D) methodology.

The study was conducted at the Mariano Marcos State University, a comprehensive institution of higher learning in Ilocos Norte. Specifically, the College of Teacher Education (CTE), located in Laoag City was the main locus of the study. The College offers two degree programs - Bachelor in Secondary Education (BSE) and Bachelor in Elementary Education (BEEd).

The said institution offers literature courses (e.g. Literature 2) as basic subjects to its General Education Curriculum on both degree programs. It is also worthy to note that the College serves as training hub in Region I for Intel Teach Curriculum and World Links Curriculum of Foundation for Information Technology Education and Development, Inc. (FIT-ED).

The researcher followed the three phases, namely: a) research and review phase; b) adapt and modify phase; and c) create and evaluate phase.

In the research and review phase, this involved two stages namely: a) preliminary preparation; and b) bibliographical research.

The preliminary preparation stage consisted of two steps, namely: 1) the conduct of preliminary research; and 2) the identification and comprehensive reading and analysis of literary poems.

The conduct of the preliminary preparation was administered to study and analyze the existing problems and conditions in the Literature 2 classes. This was done through interview with the literature teachers and their students, accompanied with observations to confirm the problems and information shared by the concerned interviewees.

In the identification of literary poems, the researcher selected 10 poems based on the suggested course syllabus specified by CHED. These poems include: a) Haiku of 
Matsuo Basho (Japan); b) The Little Rain by Tu Fu (China); c) The Road Not Taken by Robert Frost (America); d) To Whom Shall I Speak Today? by an Anonymous (Egypt); e) Sonnet 18 by William Shakespeare (England); f) Psalm 23 by King David (Hebrew); g) The Prophet by Kahlil Gibran (Lebanon); h) Telephone Conversation by Wole Soyinka (Nigeria); i) The Rubaiyat by Omar Khayyam (Persia); and j) Iliad (Book $X X I V)$ by Homer (Greece). After careful selection of the literary poems, the comprehensive reading and analysis of the selected poems followed.

In the bibliographical research stage, the researcher did an extensive reading on the practices in literature teaching, particularly the teaching of poetry. Moreover, he reviewed existing models and learning pedagogies on ICT use and considered related literatures and studies, as well as preparations of instructional materials, to derive the format, technical details and modes of presentation of the ICT-based resource kit.

In adapt and modify phase, this included activities prior to the development of the ICT-based resource kit in teaching poetry.

Based on the results of the preliminary preparation and the bibliographical research conducted in the first phase of the model, the Systematic Model for Designing ICT Plans developed by Wang and Woo [7] was adapted and modified to consider the practices and principles in literature teaching and learning and to suit the needs of the study.

Likewise, the objectives of the lessons, the strategies, the learning tasks and activities and the format of the ICT-based resource kit were designed in this phase.

In create and evaluate phase, this included two stages namely: a) writing of the ICT-based resource kit; and b) validation of the resource kit.

The ICT-based resource kit includes the facilitator's guide and the interactive compact disc (CD). The facilitator's guide contains the ICT-based plans having eight parts. This is used by the teacher to facilitate the implementation of the lessons. Meanwhile, the interactive CD contains the ICT-based lessons having the sixth part of the guide. This is used by the students to direct them to activities in an online computer-driven classroom.

After writing the materials, the researcher's adviser and the members of the advisory committee critiqued the developed ICT-based resource kit. Then, the kit was subjected to content and design characteristics validation by the panel of literature experts and ICT experts, respectively. Results and feedback from the experts served as bases for the improvement of the kit.

Two research instruments were used in the study. These included: a) The Content Validation Checklist; and b) The Design Characteristics Validation Checklist.

The Content Validation Checklist was used by the panel of literature experts in validating the content of the developed ICT-based resource kit in terms of: a) objectives; b) activities; c) instructional characteristics; and d) evaluative characteristics.

On the other hand, The Design Characteristics Validation Checklist was used by the panel of ICT experts in validating the design characteristics of the resource kit in terms of: a) introductions; b) tasks; c) processes; d) resources; e) evaluation tools; f) conclusions; and g) overall designs.

For responses in both research instruments, the given scale was used: 5: Highly Valid (HV); 4: Satisfactorily Valid

(STV); 3: Moderately Valid (MV); 2: Slightly Valid (SLV); and 1: Not Valid (NV).

In this study, computed weighted means were the statistical tools used in analyzing the data gathered. These were interpreted using the given range of interval point scores: 4.51-5.00: Highly Valid (HV); 3.51-4.50: Satisfactorily Valid (STV); 2.51-3.50: Moderately Valid (MV); 1.51-2.50: Slightly Valid (SLV); and 1.00-1.50 Not Valid (NV).

\section{RESULTS AND DISCUSSIONS}

This chapter presents the analyses and interpretations of data pertinent to the study.

\section{A. Features of the ICT-based Resource Kit in Teaching Poetry}

The ICT-based resource kit is composed of the Facilitator's Guide and the Interactive Compact Disc (CD) containing the ICT-based lessons in the teaching of poetry. The former contains ICT-based plans, which the literature teachers can use as guide in the teaching of poetry while the latter contains actual lessons and activities, which the students use during the learning process.

\section{1) The facilitator's guide}

The facilitator's guide contains ICT-based plans primarily intended for literature teachers in the teaching of poetry. The guide is patterned after the Systematic Model for Designing ICT Plans developed by Wang and Woo [7].

Parts of the facilitator's guide. Each plan contained in the guide has the following parts: a) Lesson; b) Problem Statement; c) Learning Objectives; d) Technology Required; e) Rationale of Using ICT; f) Strategies for Implementation; g) Student Assessment; and h) Reflections and Suggestions.

Lesson indicates the title and the author of the poem including the literary focus of the poem and the estimated duration allotted for the completion of the lesson. Problem Statement describes the major problem or issue to be addressed in the lesson. This serves as starting point for the use of ICT. Learning Objectives specify the intended learning outcomes at the end of the topic. Technology Required lists down all possible ICT tools that can be used for learning the topic. Rationale of Using ICT gives justification for using the selected ICT tools, particularly the added values the tools can offer and their support in the instructional process. Strategies for Implementation offer procedures and strategies on how to effectively and meaningfully incorporate the selected ICT tools into the topic learning. Student Assessment gives details on how the students' performance and outputs are evaluated. The assessment tool (scoring guide or rubric) reflects both the process and the product. Reflections and Suggestions include reflections on the learning processes, particularly learning experiences on ICT use - the appropriateness of the technology used, strengths and weaknesses of the technology, 
and possible improvement. Additionally, this provides further suggestions on how other teachers can use the lessons for other students in different contexts.

Salient features of the facilitator's guide. The guide offers salient features that are believed to address the need of poetry pedagogy by the literature teachers of the Mariano Marcos State University, College of Teacher Education.

Essential question. The essential question at the beginning of each lesson is one of the salient features of the guide. This encompasses a significant issue, major event or historically important or controversial topic. Eventually, this poses a problem that serves as starting point of teachers for the use of ICT in the teaching of poetry. Basically, the problem is authentic, challenging, open-ended, meaningful and purposeful that lends to multidisciplinary investigations.

According to Passey and Rogers [8], essential questions have proven to be an effective way of framing a course or an entire program of study.

Reasonable use of technology. This feature explains the teachers' need to choose technology and justify why it is needed for the topic, what added values the technology can offer and how the technology can support the instructional process.

In relation to the said feature, Roblyer, Edwards, and Havriluk [9] suggest the following for rationalizing the use of technology: a) high motivation; b) unique instructional capabilities; c) support for innovative instructional approaches; and d) increased teacher productivity and student knowledge construction.

Specified implementation strategies. This feature explains how teachers can effectively and meaningfully incorporate chosen technology into the topic. It elaborates on how teachers can facilitate the lessons from schema activation to evaluation. Details on ICT use are provided separately for each activity as well as for the entire lesson. This feature stipulates how an activity connects to the next activity and the reason for doing so. With this feature, the expectations and assessment criteria are also properly stated.

Authentic assessment. The guide often encourages active learning and social interaction which results in an authentic assessment. The assessment tools reflect both the process and the product. The assessment on the process examines how the students complete the learning activities or tasks, work together to complete the final product, or construct knowledge collaboratively by using the ICT. Meanwhile, the assessment of the process aims at investigating the quality of the final output or outcome.

Opportunity for reflections and suggestions. This feature is evident at the last part of every lesson in the guide. In the guide, teachers can review the appropriateness of the technology used, strengths and weaknesses of the technology, and possible improvement. Further, this feature can encourage them to provide suggestions on how other teachers can use the lessons for different target students in different contexts. These suggestions may include alternative technology, instructional methods and activities, assessment approaches, and ways to improve the use of ICT.

The previously discussed salient features are geared towards the need for poetry pedagogy.

\section{2) The interactive compact disc (CD)}

The interactive CD containing the ICT-based lessons in the teaching of poetry directs students to activities in an online computer-driven classroom.

Parts of the ICT-based lessons. Each lesson contained in the interactive $\mathrm{CD}$ has the following parts, namely: a) Logging In; b) Hyperlinking; c) Data Processing; d) Social Networking; and e) Logging Out.

Logging In activates students' background information and provides an overview of the learning goals on a topic and sets the students a stage for inquiry and further investigation. Hyperlinking aims at scaffolding the students in connecting their thoughts with the lesson. Data Processing contains the lesson proper which includes four sub-parts namely: a) Word Processing (unlocking unfamiliar words through vocabulary building activities); b) Navigating (reading the poem through the suggested web resources); c) Configuring (discussing the poem); and d) Highlighting (analyzing and discussing the dominant literary element of the poem). Social Networking comprises group activities that promote interaction, collaboration and cooperation among the students to be able to apply and deepen their understanding of the poem. This section challenges the students to produce technology-based outputs that are to be presented in class. Logging Out brings closure to the whole lesson, allowing the students to reflect and summarize what they have learned as a result of completing the whole lesson.

Notably, each lesson in the CD contains web resources for the students' scaffolds, ready-to-use downloadable worksheets for the students' answers to the activities and rubric or scoring guide for the teachers' and students' evaluations and feedback on the output.

Salient features of the ICT-based lessons. The ICT-based lessons highlight notable features that assist students in studying and learning poems.

Readily accessible online information. The literature students' access to online information is one of the salient features of the ICT-based lessons developed. This special feature allows the students to investigate more thoroughly the real world. Through the developed lessons, the students can readily access more information sources outside the classroom and can use tools to analyze and interpret such information through online systems or data logging systems. These technology systems allow them to receive feedback, refine their understanding, build new knowledge and transfer from school to non-school settings. What can be learned by the students are broadened and deepened through ICT.

Ready-to-use learning resources. Aside from the readily accessible online information offered by the ICT-based lessons, the ready-to-use learning resources are also one of its salient features. With the ICT-based lessons developed, ready-to-use learning resources are being made available for students which are ready to be downloaded by students. Once students are finished accomplishing the worksheets, they can immediately submit them through their e-mails. Hence, the developed lessons do not only offer ready-to-use worksheets but also paperless worksheets that minimize the danger of losing them since they are submitted online and are retrieved anytime by the teachers. 
Student-centered learning structure. The developed ICT-based lessons in teaching poetry possess a salient feature that helps students transform from being passive to active participants in the learning process, thus, making the learning student-centered. The lessons developed provide students learning experiences where they interact with the computer system and with other people either in person or online. Hence, the students have more control of the learning processes than their teacher.

Scaffolded learning structure. The developed ICT-based lessons have scaffolded learning structure which can be used to support the development of higher level thinking skills of students. Consequently, the lessons can provide students means to analyze data, present data, link data or information, present information in different formats, simulate environments and conditions, and support interactive communications.

Interestingly, according to Polard [10], scaffolded learning lessons allow teachers to consider a range of activities to assist their students to become critical thinkers, designers and problem solvers.

Challenging group tasks. Another unique feature of the developed ICT-based lessons is the challenging group tasks that trigger student interaction, collaboration and cooperation. With the ICT-based lessons developed, students are given project roles to perform in a particular task, which give them the opportunity to interact, collaborate and cooperate for a common goal.

Moreover, these tasks are used to reach a variety of goals including higher achievement, improved motivation and better relationships, improved social skills among students from diverse backgrounds. In addition, they are used to reach a variety of content goals ranging from automacity with facts to higher-level goals such as problem solving and critical thinking. Thus, the tasks are designed to increase involvement and participation leading to the development of collaborative, cooperative and social skills.

Eggen and Kauchack [11] claimed that using challenging tasks help students develop important skills such as turn-taking, listening, learning to disagree constructively, giving feedback, reaching consensus and involving every member in the group.

User-friendly instruction. According to Jensen [12], one of the factors that affects student learning is the atmosphere of the instruction. This means that the environment has a great impact in the learning process.

The ICT-based lessons are easy to use. The language used is appropriate to their level. Instructions are delivered in a conversational manner. Directions are easy to follow and are designed to carefully guide the students to learn things by themselves at their own rate. The flow of the lessons is systematic and the activities are well-organized. Likewise, the stimulating multimedia, interactive contents and online resources embedded in the lessons cater students with varying learning styles and needs.

The previously discussed salient features of the developed ICT-based lessons are believed to address the need of sound pedagogy by the literature teachers in the teaching of poetry.

\section{B. Content Validity of the ICT-Based Resource Kit}

One of the objectives of the study was to determine the content validity of the developed ICT-based resource kit in terms of its objectives, activities, instructional characteristics and evaluative characteristics. This was determined by the three experts in literature teaching. The results are presented in Tables 1, 2, 3, 4 and 5.

TABLE I: RESULTS OF THE CONTENT VALIDATION OF THE ICT-BASED RESOURCE KIT IN TERMS OF OBJECTIVES

\begin{tabular}{lcc}
\hline \multicolumn{1}{c}{ Criteria } & Mean & $\begin{array}{c}\text { Descriptive } \\
\text { Interpretation }\end{array}$ \\
\hline $\begin{array}{l}\text { A. Objectives } \\
\text { The objectives are: }\end{array}$ & \\
1. are specific; & 4.30 & STV \\
2. are attainable; & 4.33 & STV \\
3. are teachable; & 4.33 & STV \\
4. are observable; & 4.23 & STV \\
5. are measurable; & 4.23 & STV \\
6. are clearly stated; & 4.30 & STV \\
7. are arranged in logical order; and & 4.43 & STV \\
8. conform to the activities presented. & 4.33 & STV \\
\hline Composite Mean & $\mathbf{4 . 3 1}$ & STV \\
\hline \hline
\end{tabular}

Legend: STV - Satisfactorily Valid

Table I shows that the objectives of the developed resource kit are satisfactorily valid as manifested by the composite mean of 4.31. This means that the objectives of the lessons are specific, attainable, teachable, observable and measurable. Moreover, the objectives are clearly stated and are arranged in logical order. Furthermore, they conform to the activities presented in the materials. The result, therefore, suggests that the learning objectives of the resource kit meet the standards of what makes good learning objectives.

Such result obtained conforms with what Wang and Woo [9] stated that learning objectives should be specific, observable and measurable.

TABLE II: RESUlTS OF THE CONTENT VALIDATION OF THE ICT-BASED RESOURCE KIT IN TERMS OF ACTIVITIES

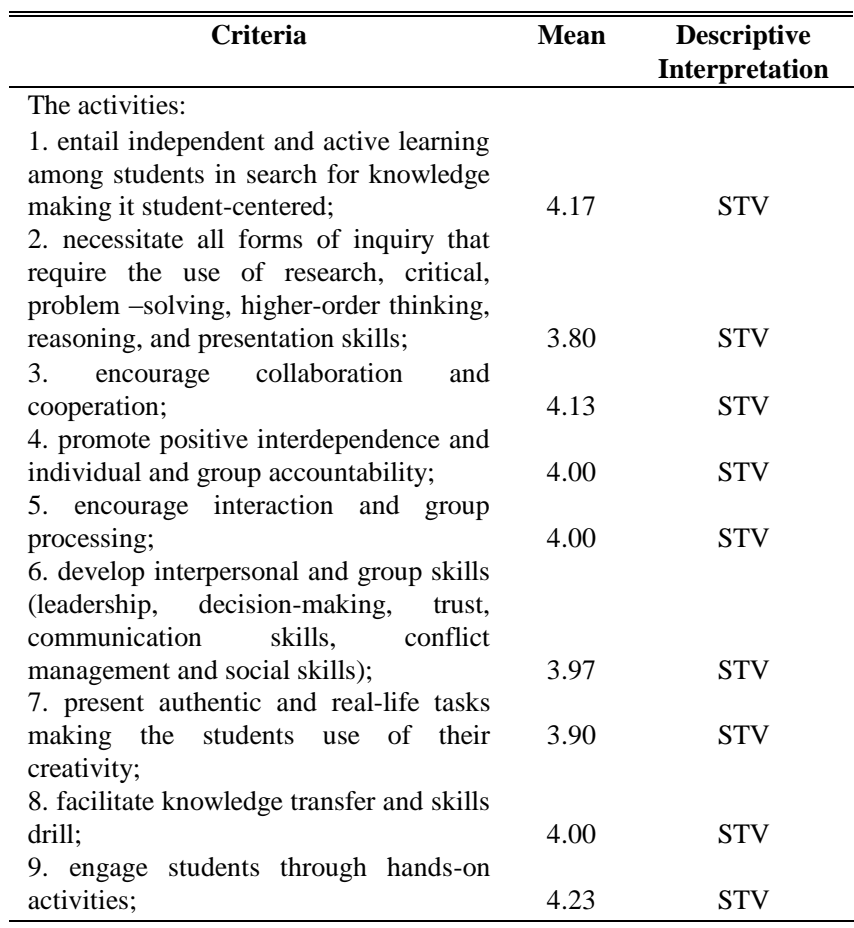




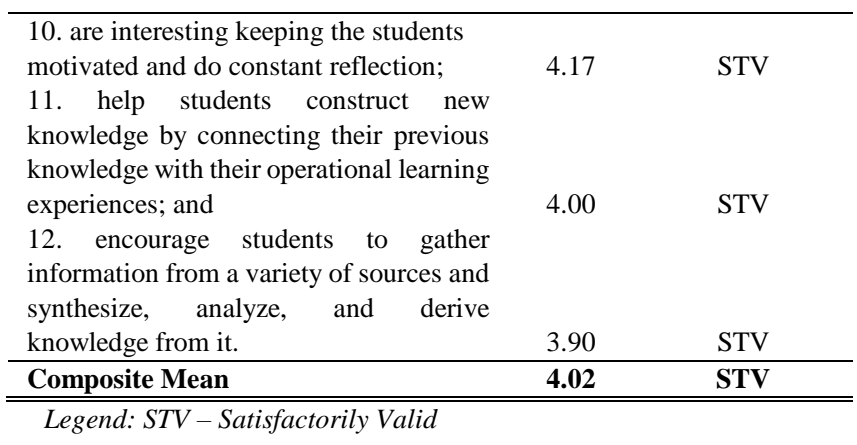

As shown in Table II, the experts also indicated that the activities are satisfactorily valid as indicated by composite mean of 4.02. Agreeably, the experts deemed the activities to engage students through hands-on activities and entail independent and active learning in search for knowledge making it student-centered. The activities are also interesting which keep students motivated and do constant reflection. They encourage collaboration, cooperation, interaction and group processing, facilitate knowledge transfer and skills drill, and help students construct new knowledge by connecting their previous knowledge with their operational learning experiences. Moreover, they promote positive interdependence and individual and group accountability. Obviously, the activities are reckoned to develop interpersonal and group skills, present authentic and real-life tasks, which make students use of their creativity, and encourage students to gather information from a variety of sources and synthesize, analyze and derive knowledge from it. The activities necessitate all forms of inquiry that require the use of research, critical, problem-solving, higher-order thinking, reasoning and presentation skills.

The result implies that the activities of the resource kit have the potentials to transform teaching and learning practices. Instructional materials, such as ICT-based, according to Kurshan and Sherman [13], have the ability to improve student learning by engaging students with the designed learning materials, the subject content and the delivery system.

TABLE III: RESULTS OF THE CONTENT VALIDATION OF THE ICT-BASED RESOURCE KIT IN TERMS OF INSTRUCTIONAL OBJECTIVES

\begin{tabular}{llc}
\hline \hline \multicolumn{1}{c}{ Criteria } & Mean & $\begin{array}{c}\text { Descriptive } \\
\text { Interpretation }\end{array}$ \\
\hline $\begin{array}{l}\text { The instructions: } \\
\text { 1. encourage creative critical thinking; }\end{array}$ & 3.97 & STV \\
$\begin{array}{l}\text { 2. arouse interests and sustain } \\
\text { attention; }\end{array}$ & 4.27 & STV \\
$\begin{array}{l}\text { 3. introduce ideas in a logical } \\
\text { sequence; }\end{array}$ & 4.10 & STV \\
$\begin{array}{l}\text { 4. promote active participation and } \\
\text { response among students; and }\end{array}$ & & \\
$\begin{array}{l}\text { 5. are clearly stated and easily } \\
\text { understood by the target learners. }\end{array}$ & 4.06 & STV \\
\hline Composite Mean & 4.10 & STV \\
\hline \hline
\end{tabular}

Based on Table III, it can be gleaned that the instructional characteristics of the resource kit are satisfactorily valid as projected by the composite mean ratings of 4.10 .
The result means that the instructional characteristics of the resource kit arouse interest and sustain attention and introduce ideas in logical sequence. In addition, the instructional characteristics are clearly stated and easily understood by target learners, promote active participation and response among students and encourage creative critical thinking.

Meanwhile, Table IV indicates that the evaluative characteristics of the resource kit are satisfactorily valid as shown by the composite mean of 3.95 .

This means that the evaluative tools used in the resource kit are authentic, logically arranged and clear and easy to understand. They judge characteristics or behaviors that are observable and measurable, jibe with the learning objectives and activities and describe attributes across defined range of abilities and are authentic.

TABLE IV: RESULTS OF THE CONTENT VALIDATION OF THE ICT-BASED RESOURCE KIT IN TERMS OF EVALUATIVE CHARACTERISTICS

\begin{tabular}{lcc}
\hline \hline \multicolumn{1}{c}{ Criteria } & Mean & $\begin{array}{c}\text { Descriptive } \\
\text { Interpretation }\end{array}$ \\
\hline The evaluation tools: & & STV \\
$\begin{array}{l}\text { 1. are authentic; } \\
\text { 2. are clear and easy to understand; }\end{array}$ & 3.74 & STV \\
$\begin{array}{l}\text { 3. are logically arranged; } \\
\text { 4. jibe with the learning objectives and }\end{array}$ & 4.07 & STV \\
$\quad \begin{array}{l}\text { activities; } \\
\text { 5. describe attributes across } \\
\quad \text { defined range of abilities; and }\end{array}$ & 3.97 & STV \\
$\begin{array}{l}\text { 6. judge characteristics or behaviors that } \\
\quad \text { are observable and measurable. }\end{array}$ & 3.93 & STV \\
\hline Composite Mean & 4.00 & STV \\
\hline \hline
\end{tabular}

Legend: STV - Satisfactorily Valid

Entirely, the composite means of 4.31, 4.02, 4.10 and 3.95 for objectives, activities, instructional characteristics and evaluative characteristics, respectively, with an overall mean rating of 4.10 , indicate that the developed resource kit is satisfactorily valid in terms of content. Moreover, the rating indicates that the resource kit could be used by literature teachers in the teaching of poetry.

TABLE V: SUMMARY OF THE RESULTS

\begin{tabular}{clc}
\hline \hline Criteria & $\begin{array}{l}\text { Mea } \\
\mathbf{n}\end{array}$ & $\begin{array}{r}\text { Descriptive } \\
\text { Interpretation }\end{array}$ \\
\hline A. Objectives & 4.31 & STV \\
B. Activities & 4.02 & STV \\
C. Instructional & 4.10 & STV \\
Characteristics & & \\
D. Evaluative Characteristics & 3.95 & STV \\
\hline Overall Mean & $\mathbf{4 . 1 0}$ & STV \\
\hline \hline
\end{tabular}

Legend: STV - Satisfactorily Valid

The evaluative characteristics of the resource kit, which received a 3.95 mean rating, were checked and revisited further improvement. Also, the comments and suggestions from the experts were considered in the revision of the resource kit. 


\section{Design Characteristics Validity of the ICT-based Resource Kit}

The design characteristics of the resource kit developed were validated by the three ICT experts. The aspects that were validated included: a) introductions; b) tasks; c) process; d) resources; e) evaluation tools; f) conclusions; and g) overall designs. The summary of the results is shown in Table 6 .

As reflected in the table, the resource kit is highly valid in terms of its introductions as the experts rated them with an overall mean rating of 4.64. This means that the resource kit's introductions describe a compelling essential question or problem and prepare learners by foreshadowing what the lesson is all about. Also, the introductions draw learners into the lesson by relating to them their interests and goals and build on learner's prior knowledge.

TABLE VI: RESUlTS OF THE DESIGN CHARACTERISTICS VALIDATION OF THE ICT-BASED RESOURCE KIT

\begin{tabular}{lcc}
\hline \hline \multicolumn{1}{c}{ Criteria } & Mean & $\begin{array}{c}\text { Descriptive } \\
\text { Interpretation }\end{array}$ \\
\hline A. Introductions & 4.64 & $\mathrm{HV}$ \\
B. Tasks & 4.47 & $\mathrm{STV}$ \\
C. Processes & 4.60 & $\mathrm{HV}$ \\
D. Resources & 4.40 & $\mathrm{STV}$ \\
E. Evaluation Tools & 4.67 & $\mathrm{HV}$ \\
F. Conclusions & 4.45 & $\mathrm{STV}$ \\
G. Overall Designs & 3.58 & $\mathrm{STV}$ \\
\hline Overall Mean & $\mathbf{4 . 4 0}$ & STV \\
\hline \hline \multicolumn{1}{c}{ Legends: $H V-$ Highly valid; STV - Satisfactorily valid; }
\end{tabular}

Legends: HV-Highly valid; STV-Satisfactorily valid;

The result suggests that the introductions of the resource kit have the capacity to make connections between what the students know and what they are about to know to make learning well-engaging. Moreover, the introductions are question-driven which lead learners to deep inquiry or investigation.

On being asked in terms of the resource kit's tasks, the experts revealed that the tasks are satisfactorily valid as signified by the overall mean rating of 4.47 . Specifically, the tasks are referenced to the learning objectives and are connected to what learners must know and be able to do to achieve the learning objectives. Likewise, the tasks require students to take a position, and/or going beyond the data given and making a generalization or creative product. They are clearly and creatively described and are doable and engaging in eliciting thinking that goes beyond rote comprehension. Noticeably, the tasks require students to do synthesis of multiple sources of information.

The result, therefore, suggests that the tasks of the resource kit pass the requirements of what makes good tasks. Thus, they could be feasible tasks for ICT-based instruction, particularly in the teaching of poetry.

The table further shows that the resource kit's processes are deemed by the experts to be highly valid as manifested by the overall mean rating of 4.60 . The result indicates that the processes necessitate group work with positive interdependence and individual accountability and assign different roles to learners to help them understand different perspectives and/or share responsibility in accomplishing the tasks. Furthermore, the processes require many or different skills, particularly $21^{\text {st }}$ century skills, and levels of thinking. The processes offer activities that are clearly related and designed to take learners from basic knowledge to higher level of thinking. Generally, the processes are clearly stated. They inform learners exactly where they are and what to do next in the lesson and provide them with strategies and organizational tools to access and gain knowledge needed to complete a given task.

Further revealed on the table is the resource kit's design characteristics validation in terms of its resources. The experts consider the resources of the materials to be satisfactorily valid as shown by the overall mean rating of 4.40. Distinctively, the resources carry weight in the accomplishment of a required task. They have a clear connection to the information needed by learners. Apparently, the resources provide up-to-date and accurate information to learners that augment the information given in printed materials. They are appropriate for the reading level of the learners. Accordingly, providing learners with unreliable, irrelevant, inappropriate and outdated resources does not help them to accomplish a given task [14].

The evaluation tools of the resource kit were also validated by the experts. As gleaned from the table, the evaluation tools of the materials are highly valid as indicated by the overall mean rating of 4.67. The experts affirmed that the evaluation tools are clearly stated and described in the form of rubrics or scoring guides. The evaluation tools clearly measure assigned or given tasks with the inclusion of qualitative as well as quantitative descriptions.

It can also be noted that the resource kit's conclusions are satisfactorily valid as shown by the overall mean rating of 4.45. Specifically, the conclusions summarize what teachers hope their students learned as a result of completing a task. They bring closure to the lesson and they clearly relate learners' knowledge to other topics or situations. Notably, they give enough information or questions for learners to attempt further study.

All effective lessons, regardless of the topic or the strategy being used, need closure or conclusion. According to Dodge [15], closure or conclusion helps students integrate and solidify their schemas and achieve a sense of equilibrium. Lesson without conclusion may lead learners into a sense of incompleteness, making the whole learning pointless, useless and aimless [11]. It is in conclusion that learners find the whole significance of the lesson to their lives.

Obviously, the experts affirmed that the resource kit's overall designs are satisfactorily valid as indicated by the overall mean rating of 3.58. This means that the graphics used in the materials give learners information or perspectives not otherwise available. Definitely, they are supportive of the given tasks and are appropriate, appealing and they fit the topics. Accordingly, the navigation is clear to learners. Differences in type size and/or color, including the use of animations are used well.

On being asked in terms of the resource kit's seamless navigation, the experts indicated it to be moderately valid, including the mechanical aspects of the materials. This is because, according to the experts, some of the links, particularly the downloadable worksheets, are broken or cannot be opened. Thus, they suggested that the researcher 
has to check and go over the links to address the problem. The researcher responsibly considered the suggestion, thereby, improving further the resource kit.

Passey and Rogers [8] stated that with the visual aspects of ICT, learners submit to better understanding and explanations, to being drawn to color and being able to remember easily.

Generally, the composite means of 4.64, 4.47, 4.60, 4.40, 4.67, 4.45 and 3.58 for introductions, tasks, processes, resources, evaluations, conclusions and overall designs, respectively, with an overall mean rating of 4.40 , indicate that the resource kit developed are satisfactorily valid. It can be interpreted from the result that the materials manifest the standards or requirements of an ICT-based instructional material. Thus, the resource kit can be recommended for use by the literature teachers to help them of their need for poetry pedagogy, particularly in the use of ICT.

Nevertheless, the overall designs of the resource kit, which received an overall mean rating of 3.58 , is checked and revisited by the researcher to further improve the quality designs of the ICT-based resource kit developed.

The comments and suggestions from the experts were considered in the revision and improvement of the resource kit.

\section{CONCLUSIONS}

In the light of the findings, it is concluded that the developed ICT-based resource kit in teaching poetry possesses salient parts and features that help address the need for poetry pedagogy.

Moreover, it is concluded that the resource kit is satisfactorily valid in terms of content and design characteristics as revealed by the literature experts and ICT experts, who validated the resource kit.

With all the indicated results and findings, it is concluded that the developed ICT-based resource kit in teaching poetry anchored on the Theory of Constructivism could address the need of literature teachers for available ICT-based material in the teaching of poetry to fully engage their students in literature classes.

\section{RECOMMENDATIONS}

Based on the findings and conclusions, the researcher offers several recommendations.

The ICT-based resource kit in teaching poetry developed should be tried out to determine its effectiveness on poetry pedagogy.

Further, the ICT-based resource kit should be adapted for use by all literature classes of MMSU for further test on its usefulness, for its modification and improvement and for wider circulation and production not only in MMSU but entire Region I.

In addition, literature teachers should be flexible in using the ICT-based resource kit. They may modify or refine some of the activities so that learning will not focus solely on ICT use and that the learning of poetry is given more importance.

Also, a teacher training orientation on ICT use should be conducted for those literature teachers who want to use the developed ICT-based resource kit. In this way, they would be equipped with the basic ICT skills necessary in the implementation of the resource kit.

Lastly, other researchers should conduct further studies on developing ICT-based materials on teaching literature (e.g. short stories, novels, essays, drama, etc.) to explore the facets of ICT.

\section{REFERENCES}

[1] M. W. Caprio. (1994), Easing into Constructivism, Connecting Meaningful Learning with Student Experience, [Online]. Available: http://haga.up.ac.za/catts/learner/2000/scheepers_mdprojects/100/the ory/construct.html

[2] E. Ibsen, "The double role of fiction in foreign-language learning towards a creative methodology," English Teaching Forum, vol. 5, pp. 132-141, 2003.

[3] M. A. Fernandez, "Cooperative learning lessons to reinforce the teaching of Literature," Unpublished masteral thesis, Mariano Marcos State University, 2011.

[4] C. Fosnot, Constructivism: A Psychological Theory of Learning, New York: Teacher's College Press, 1996, pp. 178-180.

[5] L. Vygotsky, Mind and Society: The Development of Higher Mental Processes, Cambridge, MA: Harvard University Press, 1978, pp. 190-205.

[6] R. Ora'a, "The dynamics of significant human experience in classroom teaching," A Teacher's Resource, vol. 1, pp. 36-47, 1995.

[7] Q. Wang and H. Woo, "Systematic planning for ICT integration in topic learning," Educational Technology \& Society, vol. 10, Issue 1, pp. 148-156, 2007.

[8] D. Passey and C. Rogers, The Motivational Effect of ICT on Students, Department of Educational Research: Lancaster University, 2004.

[9] M. Roblyer, J. Edwards and M. Hayriluk, Integrating Educational Technology into Teaching, 4th ed., Upper Saddle River, NJ: Prentice Hall, 2004, pp. 98-115.

[10] A. Pollard, Reflective Teaching: Informal Professional Practice, $2^{\text {nd }}$ ed., New York City: Prentice Hall, Inc., 2005, pp. 165-180.

[11] P. Eggen and D. Kauchak, Strategies and Models for Teachers, Revised ed., New York: Pearson Education, Inc., 2006. pp. 211-235.

[12] E. Jensen, Brain-based Learning, San Diego, CA: The Brain Store, 2000, pp. 102-117.

[13] A. Kurshan and E. Sherman, The Motivational Effect of ICT on Pupils, Department of Educational Research: Lancaster University, 2005.

[14] P. Wong and M. Wettasinghe, Managing IT-based Learning Environments, In S. C. Tan \& F. L. Wong (Eds.), Singapore: Prentice Hall, 2003, pp. 60-76.

[15] B. Dodge. (1995). Some Thoughts about WebQuests. [Online] Available:

http://edweb.sdsu.edu/courses/edtec596/about_webquests.html

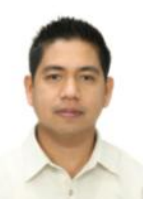

Ronald Candy S. Lasaten is from the City of Batac, Ilocos Norte, Philippines. He earned his degree Doctor of Philosophy major in Applied Linguistics at the Mariano Marcos State University (MMSU) Graduate School, Laoag City, Philippines in 2012.

$\mathrm{He}$ is presently an Associate Professor at the Mariano Marcos State University College of Teacher Education (CTE), Laoag City. He is the College Coordinator for Instructional Materials Development, Coordinator for Board Licensure Examination for Professional Teachers (BLEPT) Review and the Editor-in-chief of the CTE Research Journal. His research interests include linguistics, language, literature, language and literature teaching, language and literature assessment, instructional materials development and integration of ICT in education.

Dr. Lasaten is the vice president for research of the association of Teacher Education Administrators (ATEA), member in Asian Qualitative Research Association (AQRA), Philippine Association for Teacher Education (PAFTE), and International English Learners Training Institute (IELTI). 


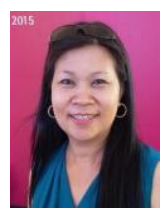

Marlina L. Lino is from Sarrat, Ilocos Norte, Philippines. She finished Ph.D. in Linguistics at the Mariano Marcos State University (MMSU) in April 2010. She has been teaching English, Literature and Humanities subjects since 1992. She has served as trainer and resource speaker in several trainings, seminars and conferences in various areas of her specialization. She has likewise presented papers both here and abroad.
At present, she holds an associate professor position and is currently the Chair of the Department of Languages and Literature of the College of Arts and Sciences, MMSU, City of Batac, Ilocos Norte. She is also the team leader of a special project of the University, Project C4: Coaching for a Contact Center Career, which is in active partnership with the Provincial Government of Ilocos Norte in the latter's drive for creating jobs for the people through the IT-BPM industry. 